\title{
POSSIBLE RESTORATIONS OF THE UPPER EXTREMITY MOTION IN TETRAPLEGIC PATIENTS - 5-YEAR CLINICAL EXPERIENCE
}

\author{
Igor Cizmar ${ }^{\mathrm{a}}$, Bohumil Zalesak ${ }^{\mathrm{b}}$, Jaroslav Pilnyc, Pavel Drac ${ }^{\mathrm{a}}$, Jana Fialova ${ }^{\mathrm{a}}$
}

\author{
${ }^{a}$ Department of Traumatology, University Hospital Olomouc, Czech Republic \\ ${ }^{b}$ Department of Plastic surgery, University Hospital Olomouc \\ c Department of Orthopaedics, Hospital Pardubice \\ e-mail: i.cizmar@seznam.cz
}

Received: October 5, 2006; Accepted: November 11, 2006

Key words: Tendon transfer/Tetraplegia/Hand grip/Spinal cord lesion/Surgical techniques

Aim: The aim of the work is to objectify the functional effectiveness of these operations and their influence on the quality of life of handicapped patients.

Method: The authors evaluate the results of reconstructive surgery restoring hand grip in a group of 15 tetraplegic patients ( 3 women and 12 men) with complete spinal cord lesion of C5-C7 segments. The average age of patients in the group is 33 (22-50) years old. The reconstructions were performed using tendon transfer and tenodesis in the forearm and hand area. The effectiveness of the transfer was assessed objectively with regard to muscle strength by measuring the restored "thumb-index finger" grip and "into fist" grip. The range of motion achieved was also evaluated. Transfer effectiveness was evaluated on the basis of subjective patients' evaluation. An ADL (activities of daily living) questionnaire by Mohammed's (1992) took into account the effect of the surgery in a whole range of common daily activities.

Results: An extended range of daily activities was evident mainly in the fields of: communication, eating and drinking and operations associated with increase in general selfcare of the patient. There was no deterioration of condition in any of the activities.

Conclusions: Up to $80 \%$ of tetraplegic patients are suitable candidates for transfers and, to a certain extent, it is possible to improve the upper limb function. In a partial function restoration of the upper limbs there is immense potential for improvement in the quality of life of these patients.

\section{INTRODUCTION}

Traumatic tetraplegia as a result of a cervical spinal cord lesion above the Th1 segment is mostly irreversible. It represents a radical change in the life of a patient who is fully dependent on help from others. Their range of daily life activities is significantly limited with regard to the functional inactivity of the upper and lower extremities.

Muscles innervated above the position of the cervical spinal cord lesion remain active. If the most common cervical spine fractures are in C4,5 segment, then - with regard to the morphology of forearm muscle innervation - only those muscles which are not involved in thumb and finger flexing and extension, and which are thus ineffective as for hand grip, remain active. With an appropriately selected combination of passive tenodesis and active transfers of these residual muscles we can achieve functional hand grip. Classification of muscles suitable for surgical reconstruction of grip and evaluation of an appropriate surgical technique were developed over past decades mainly due to the work of Moberg ${ }^{16}$. Experience and the technical achievements of present day surgical techniques show great optimism for partial movement restoration, improvement in quality of life and work capac- ity of severely paralyzed patients. Current development unambiguously proceeds with a quantitative increase in active muscle transfers, considerable transfer of paralyzed muscles to balance creation and possibly the application of electronics for paralyzed muscle control.

\section{MATERIAL AND TECHNIQUE}

\section{Classification}

Classification in tetraplegia requires periodical and detailed neurological check-ups until full stabilization of neurological condition is achieved. We classify according to the distal root segment capable of active movement with a muscle strength of grade 4 . International Classification for Surgery of the Hand in Tetraplegia is shown in (Tab. 1). Another functional motion unit of the forearm suitable for transfer is assigned in growing functional range of the classification. The classification also assesses the very important contribution of eye and skin sensibility to hand function. Most patients retain partial hand sensitivity. It is generally assumed that a two-point discrimination of at least $10 \mathrm{~mm}$ in a thumb is essential to achieve sensorimotor integration of grip. 


\section{Timing and indication for surgical operation}

Timing of surgical intervention depends on full stabilization of the patient's clinical condition, with regard to their neurological, somatic and also social state. The time interval from injury to reconstruction is usually longer than 12 months. Nowadays most patients undergo reconstruction, at earliest, 18 months after the injury. Candidates for reconstructive operation must be without spastic symptoms, respectively under pharmacological management. Another condition is correct body posture in the wheelchair, sufficient range of motion in joints, without motion limiting contractures. Other factors and indicators which determine the result of reconstruction are age, hand dominance, education and patient's motivation, associated brain injury or musculoskeletal lesions, family and social background. Not all patients are suitable candidates for such a surgical operation.

Indication of surgical procedures:

- Muscle strength of wrist extension smaller than Grade 4.

- Absence of effective finger grip into palm and "thumbindex finger" grip

\section{Contraindication}

- Low motivation and flexibility of the pacient

- Irreversible joint contractures and poor spasm control

\section{Pre-operation planning}

An individual approach to patients is absolutely essential. We choose techniques and muscles suitable for transfer according to the individual patient's needs. Most patients have their own scale of ADL importance and we adapt the choice of reconstruction techniques to it.

During the pre-operation stage - about 6 months - the patient is observed by a surgeon and a rehabilitation worker. During this period we repeatedly assess the muscle strength of residual muscle units, monitor patients' needs, their psychosomatic condition and their motivation for the operation and further cooperation during rehabilitation.

\section{Principles of operating technique}

Surgical techniques for the restoration of forearm pronation position

In most cases of tetraplegic patients the elbow extensors are plegic and flexors remain intact (according to the level of lesion). This causes a tendency towards flexion contracture and supination posture (m.biceps brachii is not only an important elbow flexor but also forearm supinator). It is possible to use rotational change of biceps tendon attachment for elimination of biceps supination effect. In this way the biceps becomes a pronation muscle, its muscle strength remains the same and functionally preferable hand posture is achieved. (Fig. 1) Patients with non-functional hand grip use bimanual grip or possibly mouth for posture correction of a held object. Generally it is possible to divide functional grip into two main types. The first grip is "thumb-index finger", where the pad of

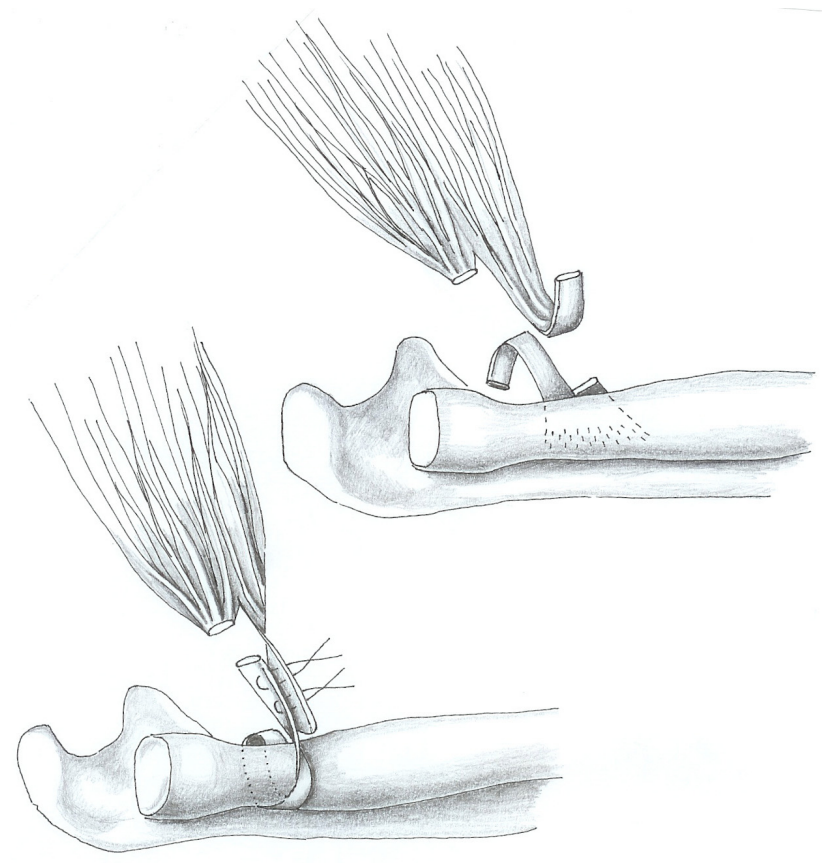

Fig. 1. Change of a biceps attachment from a supination tension to a pronation tension

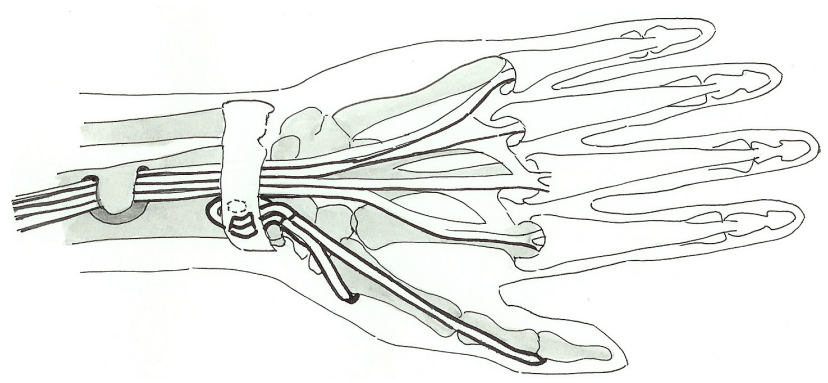

Fig. 2. Tenodesis of a long thumb extensor (EPL) and common fingers extensors (EDC).
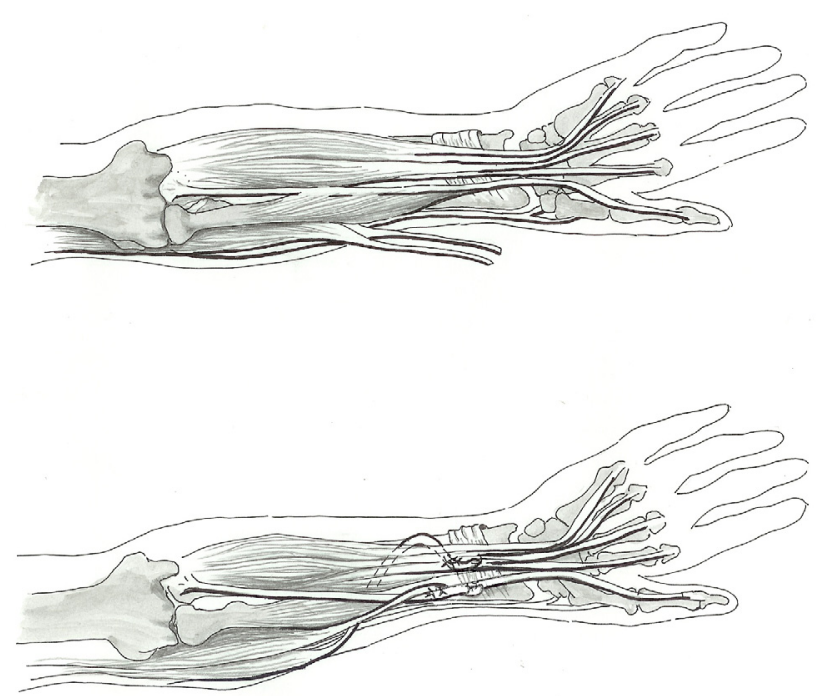

Fig. 3. Transfer of m.brachioradialis (BR) to a long thumb flexor (FPL) and transfer of long wrist extensor (ECRL) to deep fingers flexors (FDP). 
Table 1. International classification for surgery of the hand in tetraplegia.

\begin{tabular}{|l|c|l|}
\hline \multicolumn{1}{|c|}{ Sensibility } & motor group & \multicolumn{1}{|c|}{ muscules characteristic ( $\left.^{*}\right)$} \\
\hline $\mathrm{O}=$ ocular afferents only & 0 & No muscle below elbow available \\
$\mathrm{Cu}$ = cutaneous sensibility & 1 & BR \\
2 & BR + ECRL \\
3 & BR + ECRL + ECRB \\
4 & BR + ECRL + ECRB + PT \\
5 & BR + ECRL + ECRB + PT + FCR \\
6 & BR + ECRL + ECRB + PT + FCR + EDC \\
7 & BR + ECRL + ECRB + PT + FCR + EDC + thumb extensor \\
8 & BR + ECRL + ECRB + PT + FCR + EDC + thumb extensor \\
& + partial digital flexors \\
& 9 & lacks only intrinsic muscules \\
\hline
\end{tabular}

(*) A muscule must be at least grade 4 strength on the Medical Research Council scale to be considered for transfer.

Table 2. Entered data of clinical group-type of transfer.

\begin{tabular}{|l|l|c|}
\hline \multicolumn{1}{|c|}{ type of procedure } & type of clasification & number of procedures \\
\hline BR-ECRL + tenodesis FPL & O:1 & 7 \\
\hline BR-FPL & O:2 & 1 \\
\hline BR-FDP + tenodesis FPL & O:2 & 2 \\
\hline BR-FPL + ECRL-FDP & CuO:4; CuO:5 & 5 \\
\hline tenodesis EDC + EPL +APL & $\mathrm{CuO}: 5$ & 3 \\
\hline Laso technika II.-V. & $\mathrm{O}: 1 ; \mathrm{CuO}: 4 ; \mathrm{CuO}: 5$ & 5 \\
\hline Biceps & $\mathrm{O}: 1 ; \mathrm{CuO}: 3$ & 5 \\
\hline
\end{tabular}

the thumb's distal phalanx supports the lateral side of the index finger medial phalanx. The second type is a "fist grip", where the fingertips of at least the second and third fingers touch the thenar, and it is used for grabbing bigger objects.

\section{Restoration of "thumb-index finger" grip}

For reconstruction of functional thumb motion sustained active function of m.brachioradialis (BR) is absolutely essential and possible wrist extension, by means of $\mathrm{m}$. extensor carpi radialis brevis and longus (ECRB, ECRL) with a muscle strength of Grade 5. With a higher level of spinal cord lesion, when only the BR is functional, it is possible to transfer this muscle to the tendenous part $\mathrm{ECRB}^{2,6,7,17}$. In this way we can achieve active wrist extension. It is possible to achieve greater motion quality and active strength and at the same time retain active function of BR and both wrist extensors - ECRB, ECRL $(\mathrm{OCu} 3,4)$. In this case the BR is transferred to FPL and ECRL to deep finger flexors (12). Opinions on stabilizing operations on the thumb has, over time, been directed towards distal tenodesis of IP thumb joint and, conversly, a slight decline in desis of CMC thumb joint has been observed due quite frequent occurrence of complications. Attainable "thumb-index finger" grip strength measured with a dynamometer is $2-5 \mathrm{~kg}^{3,9}$.

\section{Restoration of finger flexion - "into fist"}

All patients according to classification $\mathrm{OCu} 4$ and higher belong to this group. It is possible to perform transfer of one of the functional muscles (BR, ECRL, PT) to deep flexors of II-IV finger in all these patients. As well as in our group the most frequently used is a transfer ECRL to FDP. The opinion that the most suitable 

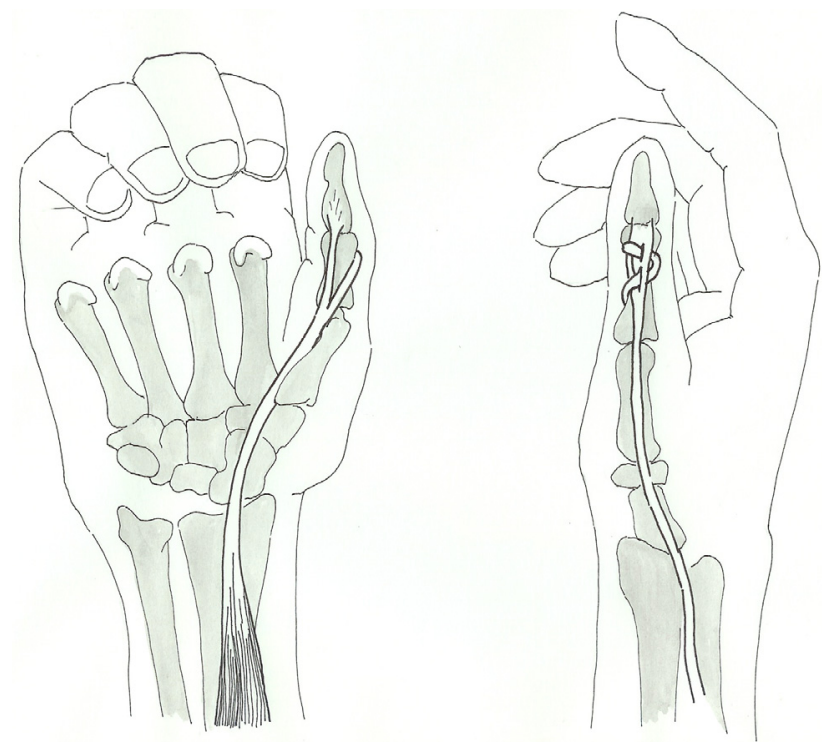

Fig. 4. Distal tenodesis of a long thumb flexor tendon for a stabilization of interphalangeal (IP) thumb joint.
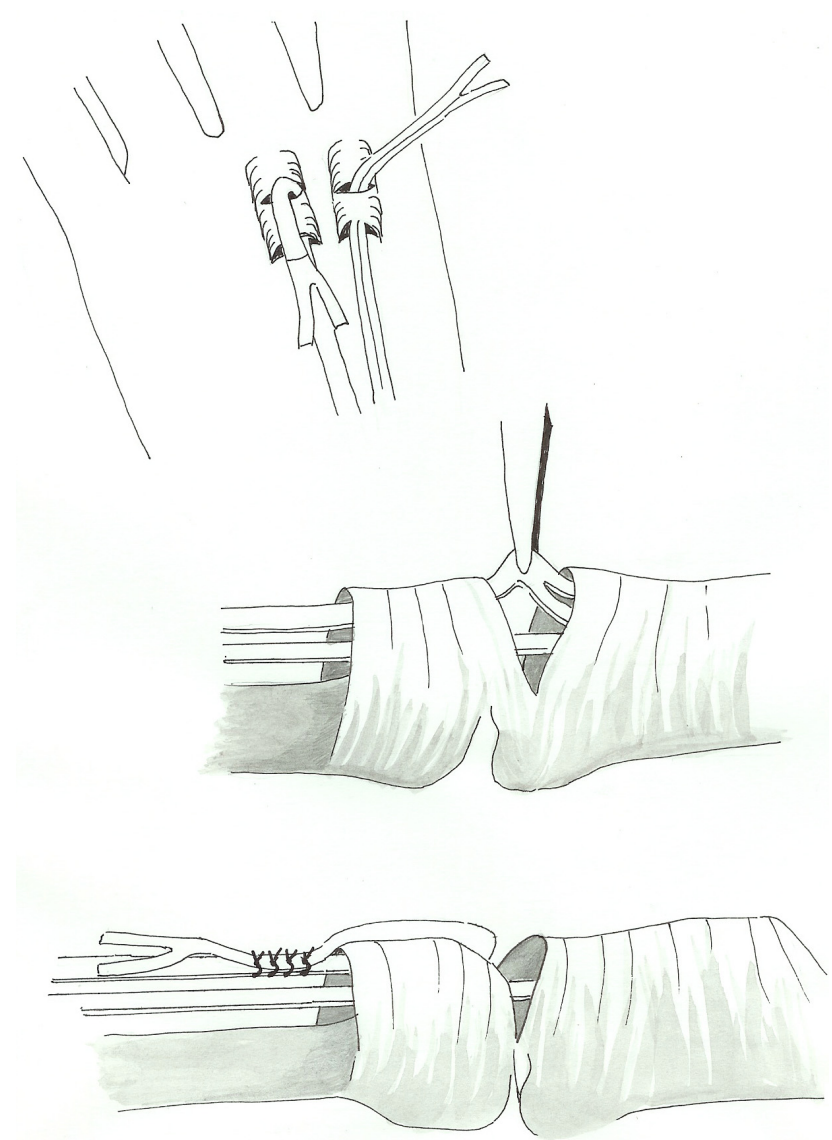

Fig. 5. The "lasso" technique according to Zancolli - it eliminates hyperextension in MP joints and improves bias for fingers flexion. method is the so-called two-stage reconstruction, according to House, has recently started to prevail. With this technique we solve fingers and thumb extension in the first stage - by tenodesis of m.extenzor policis longus (EPL) and m.extensor digitorum comunis (EDC) (Fig. 2) and in the second stage we deal with the flexor stage - transfer of selected muscles to fingers and thumb flexors (Fig. 3) in combination with distal tenodesis of the thumb IP joint (Fig. 4) and possibly stabilization of the thumb CMC joint.

We always used the transfer ECRL to FDP in our patients after prior open assessment of their muscle strength. The extensor stage was implemented inonly three patients.

\section{Surgical techniques for intrinsic hand balance restoration}

Hyperextesion posture in the MP joint of II-V fingers occurs as a result of intrinsic disbalance. This condition causes flexion in DIP and PIP after transfer of active muscle to FDP without sufficient flexion capability of the MP joint. This imperfect finger flexion does not fulfil the conditions of functional grip. The "lasso" technique according to Zancolli (Fig. 5) compensates hyperextension posture in MP joints. Though finger posture is part of favourable tension (flexion of 15-30 degrees in MP joints), hyperflexion of DIP and PIP in finger flexion is compensated and also improves cosmetic appearance.

\section{Group of patients}

Th observed group consisted of patients who underwent reconstructive operation in terms of tendon transfers and tenodeses for restoration of hand grip function. This group included 15 patients ( 3 women and 12 men) with an average age of 33 years (22-50). Spinal cord lesion occured in C5-C7 segments. Entered data of the assessed group, including the type of a transfer performed, are presented in Tab.2.

Criteria for selection of patients suitable for the study were as follows:

- All patients were at least 18 moths after an injury. Repeated complex examinations standardized according to ASIA-score in the period before reconstructive operation did not assess any neurological development or advancement in a restoration of muscle unit activity.

- The patients were mostly young active people with positive motivation and willingness to cooperate.

- The patients who had had uncontrollable spastic symptoms or functionally significant contractures were not included in the monitored group.

\section{Monitored parameters}

The effectiveness of transfer was evaluated objectively by measuring grip strength. Measurements included achieved grip strength of thumb-index finger, eventually also the grip strength of fingers into fist and the angle of the newly restored wrist extension and finaly forearm pronation. The grip strength was measured according to 


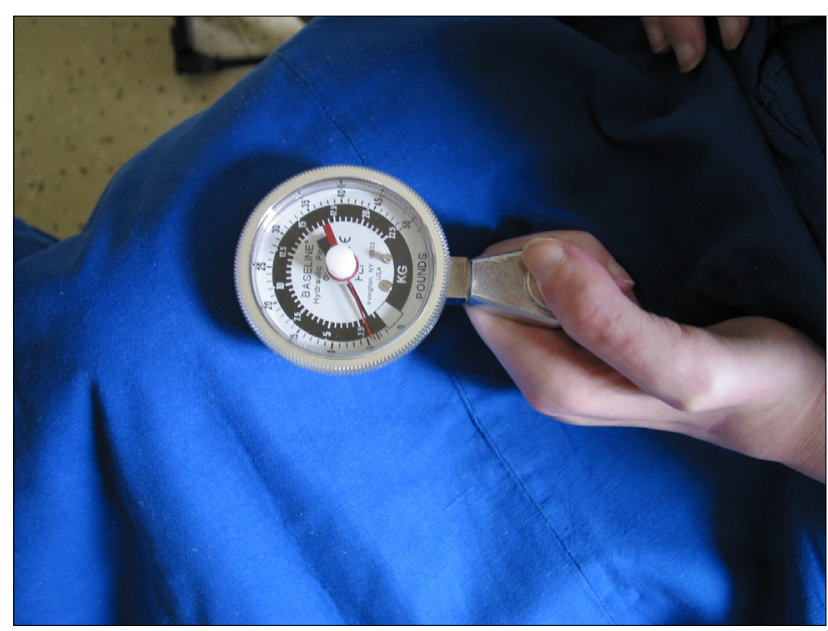

Fig. 6a. Grip strength measuring thumb-index finger with a dynamometer.

recommended standards ${ }^{15}$. The grip strength of "thumbindex finger" grip was measured with a dynamometer $(\mathrm{kg})$ and the grip strength "into fist" was measured with a tonometer $(\mathrm{mmHg}$ ) (Fig.6a,b). The achieved range of motion was evaluated with a goniometer. The effectiveness of the transfer was also assessed on the basis of a subjective evaluation by the patients. A set of goal-directed questions within the framework of a standardized ADL questionnaire took into account the effect of the operation in the full range of common daily activities. This questionnaire was given to the patients on average 10 months (6-18 months) after the operation.

\section{Statistical data processing}

The evaluated data was represented as categorised variables, where the value of improvement resp. deterioration of patients functions, was evaluated according to a five-grade ordinal scale. For comparison of differences in improvement of individual parameters the five-grade scale was simplified into three grades - "deterioration", "without change" and "improvement" of patient's perceived condition. Then, for individual parameters, the proportion of patients in a particular category was determined and also $95 \%$ reliability intervals of model applications of binomial values distribution. Pie charts, histograms and bar charts were used for descriptive visualization, supplemented by a chart of reliability intervals.

\section{RESULTS}

The ADL questionnaires, filled in by patients some time after their reconstructive operation, were evaluated and the results were summarized in collection of graphs No. 1. In this table the influence of reconstructive operation on individual activities of daily life in the group is evaluated according to Mohammed's scoring system (1992). An extended range of daily activities can be ob-

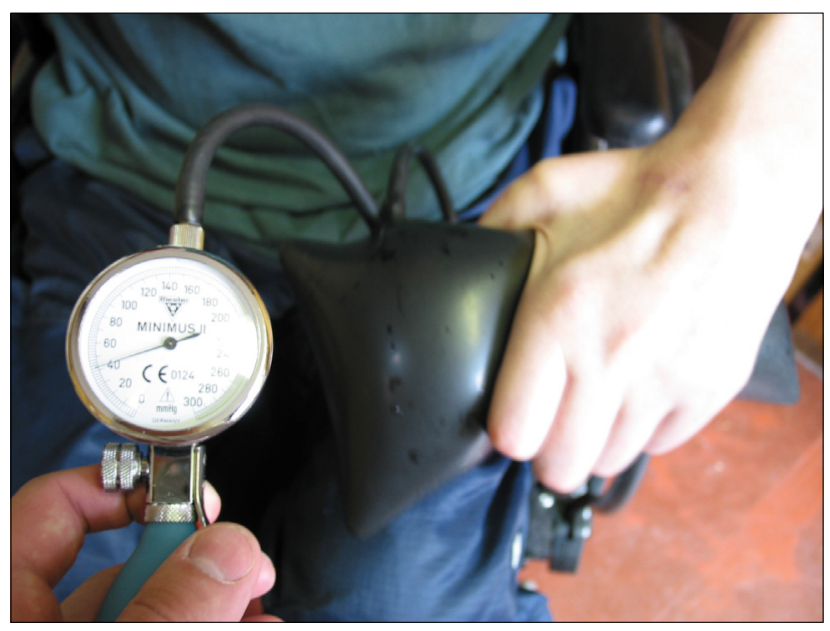

Fig. 6b. Grip strength measuring fingers into fist - a tonometer.

served mainly in the following areas: communication, eating and drinking and also increased general selfcare of the patient. Conversely, reconstructive operations have a lower influence on the following fields of activities: mobility and dressing. There was no deterioration of condition in any of the activities. In 15 patients the "thumb-index finger" grip was restored. The average muscle strength achieved between a thumb and an index finger, measured with a dynamometer, was $1.7 \mathrm{~kg}(0.2-3.6 \mathrm{~kg})$. In 7 patients the finger grip strength into palm was restored. Average muscle strength achieved, measured with a tonometer, was $23.2 \mathrm{mmHg}(20.0-27.0 \mathrm{mmHg})$. In other types of transfers the angles of achieved motion range were measured - this includes the restoration of fingers extension, the correction of MP finger joint hyperextension and the angle of achieved forearm pronation in elbow flexion. Due to the small group size the values were not further statistically evaluated. There was improvement in initial posture in all patients. Summarization of a standard indicator: weighted average for individual questions of the questionnaire shows, that our group showed an extended range of daily activities mainly in the fields of: communication, eating and drinking and that the operation increased general selfcare of the patient. Conversely, reconstructive operations had a lower influence on the fields of: mobility and dressing. Migration of KI wires during stabilization of IP thumb joint with a pin track infection and also postoperation hematoma in the wound were among the most frequent complications.

\section{DISCUSSION}

A tetraplegic patient is fully dependent on others due to insufficient hand function and $75 \%$ of patients consider this handicap more significant than plegia of the lower extremities, malfunction of emptying or sexual function (Hanson RW). Big group tests show that up to $70 \%$ of 

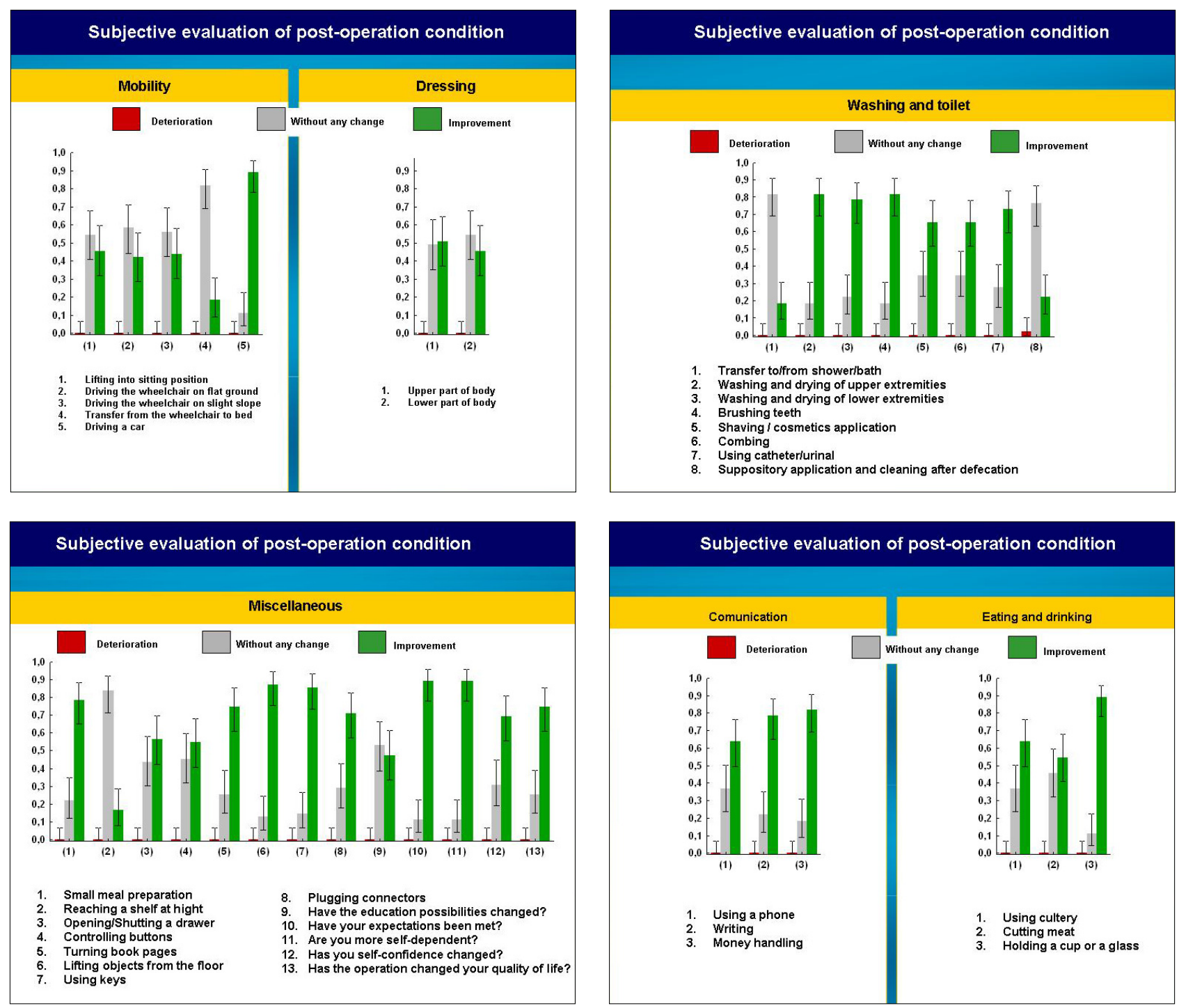

Collection of graphs No. 1. Graphic presentation of subjective results according to individual main groups of activities of daily life.

tetraplegic patients are suitable candidates for transfers and, to a certain extent, it is possible to improve upper extremity function. An extended range of daily life activities, based on partially restored hand function, significantly improves a patient's quality of life. An appropriate indication of the reconstructive operation, the operation itself and post-operative rehabilitation care are team work which a surgeon, a physiotherapist and a neurologist have to participate in. The operation itself, without quality backup rehabilitation, does not solve anything and is, on the contrary, a burden for the patient. Most studies evaluate transfer techniques in patients with a different level of lesion ${ }^{13,15,21}$. The effectiveness evaluation of individual procedures and their comparison is very difficult due to variability in patient's initial condition. All the authors involved in this matter agree on the positive influence of transfers with regard to quality of life of a tetraplegic patient. This positive opinion is not shared by some rehabilitation therapists, mostly in countries where these operations are not common and awareness of them is quite low. It is necessary to include the Czech and Slovak Republics among these countries. We are the first team in the Czech Republic (Slovak Republic too) which systematically deals with this matter. We use standardized ADL questionnaires for evaluation of the results. The questionnaires show the benefit of carrying out reconstructive operations on patients in the best way. From our own experience a wider range of hand motion, and muscle strength of grip after a reconstruction operation, do not always correspond with an extended range of ADL and thus with patient satisfaction. In our group of patients, in contrast to other studies published so far $^{1,12}$, we included all tetraplegic patients who underwent the operation and we evaluated the overall effectiveness of an interventional approach for grip solution in tetraplegic patients. In this way we have unambiguously responded to the doubts of many specialists about the effectiveness of these operations with regard to patient's quality of life. It is essential that no limit is placed on existing upper extremity function. It is possible to minimize this risk if there is 
knowledge of the matter and responsible pre-operation consideration. Reversibility of operations is also considered to be crucial by many authors ${ }^{18}$. There is no patient in our group who would have requested a reversal to their original condition. On the other hand, it is necessery to mention that this operation would be rather complicated and with some types of transfers (eg. dorsal tenodesis EDC) it is not possible to ensure that the original state could be achieved. Therefore an appropriate selection of a patient, superior pre-operation consideration and experienced rehabilitation background are a prerequisite for a successful operation and further post-operation progress. In the past rehabilitation focussed on functional hand creation was based mainly on splint application and sporadically on surgical extensive arthrodesis and passive tenodesis with the aim of creating an inner splint at the cost of joint motion limitation. On the basis of long-term clinical and experimental development tendon transfers are increasingly used as essential surgical rehabilitation of a tetraplegic hand ${ }^{4,10,11}$. Initial works on surgery of a tetraplegic hand did not deal with any reconstruction of extensor hand function. ${ }^{20}$. The trend towards complex solutions of grip function (i.e. both extension and flexion) systematically occurs only in later works ${ }^{5,8,14,15}$. Current development unambiguously proceeds with a quantitative increase of active muscle transfers, considered transfer of paralyzed muscles and balancing creation??? with the application of electronic operation of the paralyzed muscle ${ }^{19}$.

\section{CONCLUSION}

The main thesis of tetraplegic hand reconstruction is best represented by a statement which was expressed by Sterling Bunnell: "If you have nothing, a little is a lot". There is a huge potential for improvement of patients'quality of life in restoration or improvement of grip function of a hand. In patients from our group we have shown extended range of $A D L$, mainly in the fields of: communication, eating and drinking and that the operation increases general selfcare of a patient. Conversely, reconstructive operations have a lower influence on the fields of: mobility and dressing. There was no deterioration of a condition in any of the activities monitored. Our results and also foreign experience entitle us to a much more active approach to tetraplegic hand reconstruction and integration of this matter into common standard care of tetraplegic patients.

\section{REFERENCES}

1. Beasley RW. Surgical treatmentof hands for C5-C6 tetraplegia. Orthop Clin North Am 1983; 14:893-904.

2. Cizmar I, Wendsche P, Visna P, Francu M, Kocis J. Surgical rehabilitation of the upper extremity in tetraplegic patients - Principles and initial experience. Rehabilitace a Fyzikalni Lekarstvi 2003; 10(2):65-71.

3. Cizmar I, Wendsche P, Brychta P, Visna P, Kocis J, Mensik I.(2003) Reconstruction of functional handgrip in traumatic tetraplegia. Acta Chirurgiae Plastice 2003; 45(4):119-23.

4. Curtis RM. Tendon transfers in the patient with spinal cord injury. Orthop Clin North Am 1974; 5:415-32.

5. Ejeskar A, Dahlgren A, Friden J. Clinical and radiographic evaluation of surgical reconstruction of finger flexion in tetraplegia. $\mathbf{J}$ Hand Surg 2005; 30(4):842-49.

6. Freehafer AA, Mast WA. Transfer of brachioradialis to improve wrist extension in high spinal-cord injury. J Bone Jont Surg 1967; 49A:648-52.

7. Freehafer AA, Packham PH, Keith MW. The brachioradialis: Anatomy, properties and value for tendom transfer in the tetraplegic. J Hand $\operatorname{Surg}(\mathrm{Am})$ 1988; 13:99-104.

8. Friden J. New concepts in reconstruction of arm and hand function in tetraplegia - Basic research and clinical application. Handchirurgie, Mikrochirurgie, Plastische Chirurgie 2005; 37(4): 223-29.

9. Gasel J, Warers R, Gellman H. Transfer of the pronator teres tendon to the tendons of the flexor digitorum profundus in tetraplegia. J Bone Joint Surg 1990; 72A:427-32.

10. House JH, Shannon MA. Restoration of strong grasp and lateral pinch in tetraplegia: a comparison of two methods of thumb control in each patient. J Hand Surg 1985; 10A(1):22-9.

11. Hentz VR, Brown M, Keoshian LA. Upper limb reconstruction in quadruplegia: functional assessment and proposed treatment modifications. J Hand Surg(Am) 1983; 8:119-31.

12. Kelly CM, Packham PH. Postoperative results of opponensplasty and flexor tendon transfers in patient with spinal cord injury. $\mathbf{J}$ Hand Surg (Am) 1985; 10:890-94.

13. Lamb DW, Chan KM. Surgical reconstruction of the upper limb in traumatic tetraplegia. A revien of 41 patients. J Bone Jont $\mathrm{Surg}(\mathrm{Br})$ 1983; 65:291-98.

14. Leclercq C, Lemouel MA, Albert T, Surgical rehabilitation procedures of the upper limbs in tetraplegic patients. Handchirurgie, Mikrochirurgie, Plastische Chirurgie 2005; 37(4):230-37.

15. McDowell CL, Moberg EA, House JH. The second international conference on surgical rehabilitation of the upper limb in tetraplegia. J Hand Surg (Am) 1986; 11:604-08.

16. Moberg E. Surgical treatment for absent singel-hand grip and elbow extension in quadriplegia. Principles are preliminary experiences. J Bone Jont Surg 1975; 57A:196-206.

17. Murray WM, Hentz VR, Friden J, Lieber RL. Variability in surgical technique for brachioradialis tendon transfer: Evidence and implications. J Bone Jont Surg A 2006; 88(9):2009-16.

18. Rothwell AG, Sinclair SW. Upper Limb Tendon Surgery for Tetraplegia. Operat Orthop Traumatol 1997; 9:199-212.

19. Rupp R, Gerner HJ. Neuroprosthetics of the upper extremity Clinical application in spinal cord injury and future perspectives. Biomedizinische Technik 2004; 49(4):93-8.

20. Wilson JN. Providing automatic grasp by flexor tenodesis. J Bone Joint Surg 1956; 38A:1019-24.

21. Zancolli E. Surgery for the quadruplegic hand with active strong wrist extension preserved: a study of 97 cases. Clin Orthop 1975; 112:101-13. 